\title{
Constructivism Theory and Translation Teaching
}

\author{
Saihanqiqige ${ }^{1, a,{ }^{*}}$ \\ ${ }^{1}$ Editorial Department, Journal of Chifeng University, Chifeng University, Chifeng, \\ China \\ a1399789355@qq.com \\ ${ }^{*}$ Corresponding author
}

Keywords: Constructivism, Translation course, Classroom teaching.

\begin{abstract}
According to the new standard of English teaching reform, Applying theoretical insights from constructivism to reexamination of how translation has been taught, this paper identifies typical problem in the current approach and proposes a new pedagogical model of improving translation teaching under the guidance of constructivism. It emphasizes the importance of cultivating the students' initiative in the learning process and calls on the instructors to pay special attention to developing the students' cognitive abilities so as to help them become more effective in the construction of new knowledge.
\end{abstract}

\section{Introduction}

In most of the translating classes in our country, instructors are still lecturing on the platform while students are just listening on their seats, which is the traditional pattern of cultivating the students' translation skills. We are always keeping to the adoption of conventional ways of teaching vocabulary, grammar, idioms and figures of speech, introducing the translating criteria, comparing the different sentence structures, providing examples in introducing the translation methods and techniques, or randomly selecting some fragments of articles written by some famous authors for the use of practice during the class, giving reference versions afterwards. The textbooks are much the same with only some trivial differences, compiled by the well-known linguists, either belonging to the grammar school or to the function school. This approach is, of course, of great importance and we ought to stick to it in the past, at present and in the future. What we are discussing and will reform is the teaching model and the teaching effect, and most of all, the students' passive state of learning process. In such a conventional class, what we are lack of are active interaction and cooperation. The rationales, principles, experiences and skills cannot be passed on and accepted effectively. These are all the disadvantages in the traditional translating class. It triggered our thinking-How to design the translating courses in the light of modern teaching methodology? How to produce a student-centered model of translating classes? How to change the function of the teachers from instructors to directors? How to activate the course-book and the rules, theories, methods and skills and make them alive in the process of learning? And last but not least, how to make full use of the advantages of translating class so as to open a fresh field for their developing interest, showing values, accumulating experiences, constructing knowledge and appreciating the unique glamour of English as well as understanding the differences between English and Chinese. 


\section{Constructivism Theory}

Constructivism may be considered an epistemology (a philosophical framework or theory of learning), which argues humans construct meaning from current knowledge structures. These arguments about the nature of human learning guide constructivist learning theories and teaching methods of education [1]. Constructivism values developmentally-appropriate facilitator-supported learning that is initiated and directed by the learner. Constructivism is based on the idea that learners do not wait passively to be filled up with by knowledge, but actively built or construct their own knowledge when the information comes in to contact with the existing knowledge developed by learner's previous experience [2].

Constructivism is considered to be one of the most prosperous learning theories at present. It focuses on the subjective recognition of the learners more than all the previous theories in the history. Furthermore, it puts more emphasis to constructing an environment in which the learners probe into the knowledge actively rather than passively.

In the study of every terrain, theory is as important as practice. In my opinion, the constructivism, originating from cognitivism, is of much guiding significance to our translating classroom teaching. The goal of teaching is to help the learners transform the exterior objective things (knowledge and its structure) into interior cognitive structure. The purpose of learning is for an individual to construct his or her own understanding, not just memorize the so-called "right" answers. It differs much from the previous behaviorism - the idea that the scientific study of human's mind should be based only on outward behavior and physical states, not on people's reports of their thoughts and feelings. The behaviorists holds that the goal of the education lies in handing down the knowledge to the learners, whose task is to reach the goal set by the educators. It neglects the psychological process of the learners in the course of knowledge transmitting. This defect is realized by more and more people after many years of practicing. In the 1960's, cognitivism took the place of behaviorism and became the leading theory. More attention is concentrated on how knowledge is processed and comprehended in the mind. The improvement of this theory gave rise to a branch of cognitivism-constructivism.

Education is not what the teachers give but is a natural process spontaneously carried by carried out by human individual, and is acquired not by listening to words but by the experiences upon the environment[3]. That is to say, knowledge is obtained from the active construction of the students. Just like what is illustrated by a wide-spread saying in the foreign language study field: A language is acquired by the students, not implanted by the teachers. In effective class teaching, instructors guide the students to learn actively and willingly. Teachers are just organizers as well as cooperators, while students are carrier of knowledge and the subject of learning. Therefore, the learning process should be a mutual action between the teachers and students.

According to Von Glasersfeld (1995), motivation to learn is strongly dependent on learner's potential for learning. These feelings of competence and beliefs in their potential to acquire knowledge are affected by such factors as time, space and environment [4]. Emotion is devoted into this process and it is closely related to the experience; positive feelings produce pleasure and excitement, which are transformed to motivation that inspires the students to study more diligently; a democratic and harmonious atmosphere, a comprehension of the strength of knowledge, constant 
success and progress etc., constitute the necessary prerequisites; teachers' assessment is also very important in leading the students to construct the knowledge in their mind.

The goal of constructivism is to foster a life-long learner, who is good at self-control, self-regulation, self-analysis and self-assessment. A general assumption of contructivist approaches is that all learning is discovered not taught, even if teachers tell students something, students are still required to perform mental operations with existing information to make the new knowledge their own. As a matter of fact, this is a competence of being capable of making good use of learning strategy, i.e. how to study. As an organizer and a guide of study process, teachers ought to have some idea of how students study as well as what they study.

Bauersfeld (1995) argues that teachers should play an active role in learning process turning their roles into facilitators and help the learners get to their own understanding and construction of knowledge [5]. In the students-centered pattern class, teachers, can only be considered to be, in a broad sense, part of the study environment, which goes assist in the active study of the learner. Individuality is emphasized in this theory. For a long time, too much attention has been put on the development of group and general characters, and individual diversities are often neglected. Learning process takes on the form of duck-stuffing or Examination Paper Sea. It has nothing to do with the interior requirements and subjective behavior. What we teachers should do is to design every class on the basis of everyone's individuality, providing them with a vast space, in which they can show their talents and develop their personalities so as to achieve the ultimate goal-developing everybody's competence.

\section{Teaching of Translation under the Guidance of Construstivism}

Based on the theory, in our translating class, I think we teachers may follow the 5 ways below:

\section{Improve Interactivities in Translating Class, and Have the Students Learn the Techniques in "Translating"}

According to constructivism, learning is a process of constructing meaningful representations and making sense of learner's experiential world and In the process of learning, they should be seen as observers, participants, even agents who actively transform and construct the knowledge in the pattern that fit them. Translating class is characterized by its practicality, and therefore the learners need to construct their knowledge through a great amount of practice. Before each class, teachers should design various tasks in advance so as to lead the students participate in the teaching process actively. Students acquire the methods and skills through exercises. This is just the opposite of the traditional class, in which methods and techniques are mechanically imparted, followed by assignments in or out of class to enhance their translating ability.

In practice, teachers can take students' participation into account in designing every class. For example, have them choose a number of sentences or passages from the textbooks, such as Fundamental English, Advanced English and so on, to practice translating and even ponder what they have translated from a new perspective and tell the new methods and techniques in use; Pick up some classical fine articles from extracurricular reading materials for appreciation; begin a new chapter by doing translating exercises first, and then provide the students with their more standard explanation. On the basis of this, teachers explain and analyze the principles and 
techniques, so that students could construct their knowledge more definitely and more systematically. The teaching goal is achieved up to the standard in such a way in the end.

\section{Stress Assessment Effect and Have the Students Experience Regulations in the Course of Translating}

According to the theory of constructivism, teacher's assessment about each of the student's performance plays the most important role in building up positive feelings toward learning. As is often the case, students are eager to get teacher's praise after they think they have done well in translating. It is advisable for the teachers to try every possible way of praise instead of just such formal ones as "very good, not bad, right, correct" etc., which are too rigid and simple to stimulate their passion for further practice and study. So we should be fully aware of the strength and glamour of positive assessment, trying our utmost to make the teaching ways attractive, teaching contents inspiring, teaching methods colorful to make learning process a kind of pleasure.

In translating textbooks in use, in spite of a large number of cases of excellent translation, compilers stress translation theory and rules. They are rational but rigid, definite but still, guiding but boring. I think it considerably effective that we combine the theory together with the comment and analysis of student's work naturally and let the perceptual knowledge in the course book meet with students' wisdom. In such a way, knowledge is deeply and stably rooted in their mind.

\section{Focus on the Learning Process, and Have the Students Accumulate Experience in "Translating" Process}

Constructivism stresses the subjective cognition of learning and experience accumulation. Knowledge is the reasonability of the individual experience and new knowledge's construction is based on the previous experience. In spite of the absence of theories, students are able to turn a material into target language, depending on their experience. Therefore, experience is as indispensible as constructing translation knowledge.

In our design of class-teaching, we should pay attention to the integration of learning process and teaching goal, and provide help to the students in order to enrich their experience. Furthermore, we should help them cultivate their learning strategy awareness. An effective strategy is a half success, in my opinion.

\section{Encourage Autonomous Learning and Have the Students' Competence Evolved Out of Constant Practice of Translating}

Modern educational concepts emphasize "students-centered pattern" and schools should provide an environment that is helpful to each individual's development. Cultivating students' abilities of acquiring knowledge, of thinking independently and of creating new ideas is what our Teaching Program of College English regulates. To reach this aim, teachers should turn their role and perform as facilitators in class not giving a didactic lecture covering the subject matter, but guiding the students get to his or her own understanding of the subject. In the process of learning, teachers should turn the role of giving answers into providing guidelines and creating the environment for the students to help them arrive their own conclusions. We should keep probing into this topic in our translating teaching. As for me, a teacher of translation class, I am often enlightened by some excellent versions of my students. Although I am sometimes challenged or even denied, I still show my appreciation, 
encouraging their creativity and enthusiasm. The key point is not whether these answers are correct or not, but their awareness of autonomous study, their thought and practice, their experience accumulated through practice and their learning ability formed through experience.

\section{Provide the Students with Excellent Translating Versions by Some Well-known Translators for Them to Appreciate and Make Comparisons with Their Own}

Students may try to find the gap between the two versions and then do their best to fill the gap each time. As we often say, the power of examples is infinite. In the course of appreciating, analyzing, comparing and imitating, their ability of translating is enhanced. All these versions can be nutrition as input material accumulated in the course of enjoyment, and considerable improvement in translating as output effect is supposed to be produced at length.

This has proved to be a best way during my teaching in the past few rounds of teaching. Take the translation of Fortress Besieged translated by Jeanne Kelly for example, I assigned the intensive reading before the students' translating without reading the English version, and then had them translating some of the passages, exchanged between the students themselves, finally gave them Jeanne Kelly's. What the students found out was that the skill and art of translation must be cultivated through a large amount of practice and research of excellent translators' work. Classical works do create unimaginable favorable influence on the students translating practice,

In a word, constructivism adds a refreshed content to the conventional teaching practice, providing an updated pattern for classroom-teaching and expound a new concept of study to the students who are accustomed to accepting knowledge passively. It brings us new enlightenment and experience in our translation classroom teaching.

\section{References}

[1] Piaget, J. (1968). Biology and Knowledge: An Essay on the Relations Between Organic Regulations and Cognitive Processes. Translated(1971). Chicago: University of Chicago Press.

[2] Cobb, Paul (1996). Where is the mind? A coordination of sociocultural and cognitive contructivist perspectives. In. C.T.Fosnot.(Ed.). Contructivism: Theory, Perspective, and Practice. New York: Teachers College Press.

[3] Montessori, Maria. (1913).The Montessori Method, Pedagogical Anthropology, The Advanced Montessori Method-Spontaneous Activity in Education and The Montessori Elementary Material. New York: Frederick A. Stokes Company.

[4] Von Glasersfeld, Enrst. (1995). Piaget contructivist theory of knowing. In Radical constructivism: A way of knowing and learning. London: The Falmer Press.

[5] Bauersfeld, H. (1995). The structuring of the structures: Development and function of mathematizing as a social practice. In: L. P. Steffe \& J. Gale (ed.), Constructivism in education (p. 137-158). Lawrence Erlbaum Associates, Publishers. 